\title{
Spatial pattern and temporal evolution of glacial terminations of the last $800 \mathrm{ka}$
}

\author{
Emilie Capron ${ }^{1,2}$, N. Vázquez Riveiros ${ }^{3}$, F. He ${ }^{4,5}$, A. Jacobel ${ }^{6}$ and X. Zhang ${ }^{7}$
}

\section{Montreal, Canada, 18-20 October 2016}

The second QUIGS workshop brought together 28 delegates to assess current knowledge and research needs on the spatio-temporal patterns of climate forcing responses and feedbacks that characterize glacial terminations, i.e. transitions between glacial and interglacial periods.

\section{Presentations and discussions outlined} common features and differences between terminations. Similarities include nonlinear, multi-millennial scale changes in key climatic indicators, e.g. decreased global ice volume, atmospheric greenhouse gas concentration rise, surface temperature increases and Asian monsoon intensification. However, amplitude and duration of terminations are variable.

Transitions initiate at various glacial ice sheet states and progress under a variety of orbital forcing scenarios (Fig. 1)

Numerous presentations evidenced increased record availability and understanding for Terminations I (TI) and II (TII). However, results from the low latitudes (Africa, South America) and outside the North Atlantic basin (Pacific, Southern Ocean) highlighted regional variability, emphasizing the need for further constraints and careful interpretation in less-explored regions.

Millennial-scale events are a crucial part of the dynamics of terminations. Terminations include periods characterized by Ice-Rafted
Debris (IRD) deposition in the North Atlantic under Heinrich Stadial-like conditions (Fig. 1), likely associated with substantial Atlantic Meridional Overturning Circulation (AMOC) weakening. Each termination seems to feature a sharp increase in $\mathrm{CH}_{4}$ and in Asian monsoon strength, coinciding with the end of the main $\mathrm{CO}_{2}$ and Antarctic temperature increases. Evidences indicating sub-millennial-scale changes occurring at high and low latitudes in association with Heinrich Stadials (HS) 1 and 11 are increasing. Although millennial-scale investigations across older terminations are emerging, records are still scarce, and many have insufficient resolution to allow identification of abrupt climate changes.

Establishing the deglacial sequence, its regional fingerprint and the phasing with respect to orbital forcing beyond $\mathrm{TI}$ and $\mathrm{TII}$ requires paleoclimatic records of higher temporal resolution and improved chronologies, especially since the fingerprint of the Younger Dryas cooling and Bølling warming across TI does not appear as a consistent feature of older terminations. New ice core absolut age markers and precise radiometric dates on Asian speleothems (Cheng et al. 2016), now available for the last $700 \mathrm{ka}$, will represent useful anchors to improve paleoclimate record chronologies.

Modeling results were also a key part of the discussions. Initiatives by several climate

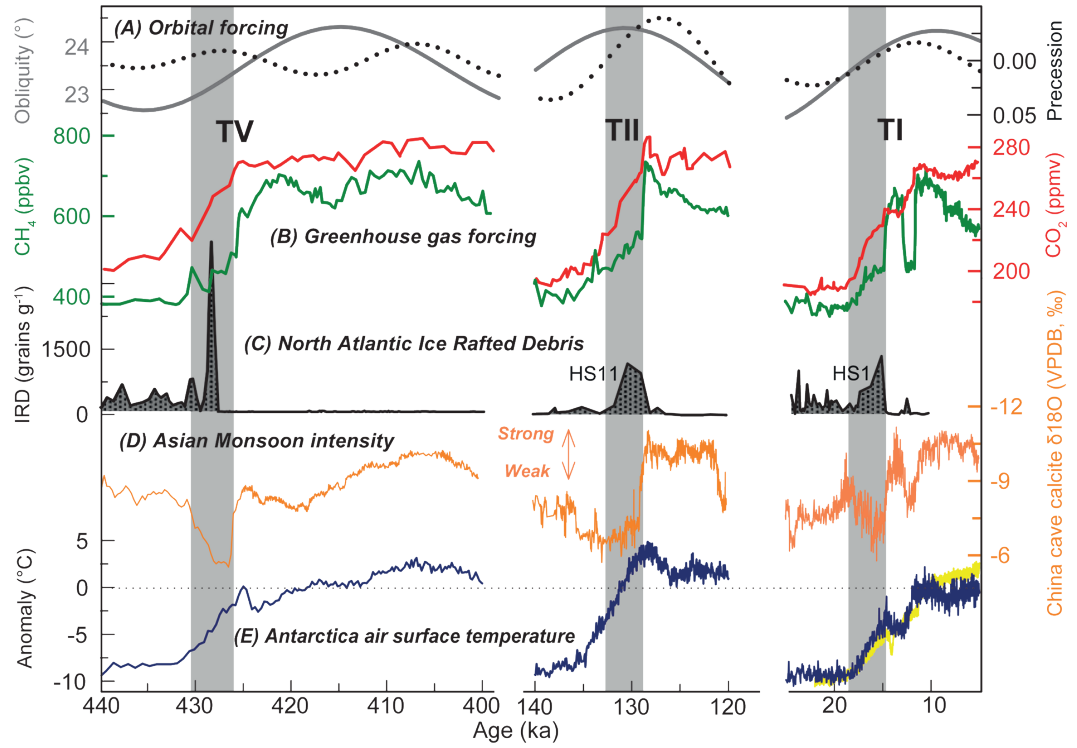

Figure 1: Terminations I (TI), II (TII) and V (TV) forcing and climatic parameters. (A) Orbital and (B) greenhouse gas forcing (Bereiter et al. 2015; Loulergue et al. 2008), together with records of (C) ice rafted debris, (D) Asian Monsoon intensity (Cheng et al. 2016), and (E) Antarctica air temperatures (Jouzel et al. 2007). TI: NA87-27 records (Waelbroeck et al. 2001) TII and TV: ODP-980 records (McManus et al. 1999); Transient surface temperature modeled with CCSM3 are shown in yellow (He et al. 2013). Temperature records represent anomalies relative to the last millennium. Grey bars indicate intervals characterized by substantial North Atlantic IRD deposition and weak Asian Monsoon.

modeling groups provide a dynamic framework to explain TI millennial-scale events (Fig. 1) and exploratory simulations for TII are in progress. A QUIGS paper in preparation will provide a framework and recommendations for the upcoming TII transient simulations. This effort will complement the TI deglaciation experiments of PMIP4, allowing an evaluation of the similarities and differences in the climate system response during $\mathrm{TI}$ and $\mathrm{TII}$ in concert with paleoclimate records.

Constraining the size and spatial distribution of ice sheets during the penultimate glacial maximum remains a challenge. New data will complement recent modeling efforts to describe the interaction between insolation and ice sheets and its role in pacing terminations. The proposed statistical models of orbitally driven terminations raised questions on the role of insolation during "failed" terminations. Further constraints are also required on the glacial carbon reservoir, and the mechanisms responsible for its modification across $\mathrm{T} 1$ remain debated.

The next QUIGS workshop focussed on interglacials of the $41 \mathrm{ka}$-world and the Middle Pleistocene Transition. It took place 28-30 August 2017 on the Greek island of Lesvos.

\section{ACKNOWLEDGEMENTS}

NVR acknowledges funding from the European Research Council under the European Union's Seventh Framework Programme (FP7/2007-2013 Grant agreement $n^{\circ} 339108$ ).

\section{AFFILIATIONS}

'British Antarctic Survey, Cambridge, UK

${ }^{2}$ Centre for Ice and Climate, University of Copenhagen, Denmark

LLaboratoire des Sciences du Climat et de

I'Environnement, Université Paris-Saclay, Gif-Sur-Yvette, France

Center for Climatic Research, University of Wisconsin-

Madison, USA

${ }^{5}$ College of Earth, Ocean, and Atmospheric Sciences,

Oregon State University, Corvallis, USA

${ }^{6}$ Columbia University, Lamont-Doherty Earth

Observatory, New York, USA

Alfred Wegener Institute, Bremerhaven, Germany

\section{CONTACT}

Emilie Capron: capron@nbi.ku.dk

REFERENCES

Cheng H et al. (2016) Nature 534: 640-646

Bereiter B et al. (2015) Geophys. Res. Lett.: 42 , doi:10.1002/2014GL061957

He F et al. (2013) Nature 494: 81-85

Jouzel J et al. (2007) Science 317: 793-796

Loulergue L et al. (2008) Nature 453: 383-386 McManus J et al. (1999) Science 283: 971-975 Waelbroeck C et al. (2001) Nature 412:724-728 